\title{
First report of TEM-104-, SHV-99-, SHV-108-, and SHV-110- producing Klebsiella pneumoniae from Iran
}

\author{
Shahram Shahraki-Zahedani ${ }^{[1],[2], ~ S h a h n a z ~ R i g i ~}{ }^{[2]}$, Mohammad Bokaeian ${ }^{[3]}$, \\ Alireza Ansari-Moghaddam ${ }^{[4]}$ and Mehdi Moghadampour ${ }^{[2]}$
}

\author{
[1]. Infectious Diseases and Tropical Medicine Research Center, Zahedan University of Medical Sciences, Zahedan, Iran. \\ [2]. Department of Microbiology, School of Medicine, Zahedan University of Medical Sciences, Zahedan, Iran. \\ [3]. Department of Laboratory Sciences, School of Paramedical Sciences, Zahedan University of Medical Sciences, Zahedan, Iran. \\ [4]. Health Promotion Research Center, Zahedan University of Medical Sciences, Zahedan, Iran.
}

\begin{abstract}
Introduction: Extended-spectrum beta-lactamases (ESBLs) are bacterial enzymes capable of hydrolyzing beta-lactams. The aim of this study was to describe the prevalence of TEM- and SHV-type ESBL-producing Klebsiella pneumoniae strains in Zahedan, Southeast Iran. Methods: A total of 170 non-repetitive K. pneumoniae strains were collected from patients referred to three teaching hospitals of Zahedan. Antibiotic susceptibility testing was determined for 17 antibiotics using the Kirby-Bauer disc diffusion method. The frequency of ESBL-producing strains was calculated, and minimum inhibitory concentrations of ESBLproducing strains were determined for cefotaxime, ceftazidime, ceftriaxone, and cefpodoxime. The presence of $b l a_{\mathrm{TEM}}$ and $b l a_{\mathrm{SHV}}$ genes was tested in all ESBL-producing strains using polymerase chain reaction and DNA sequencing. Results: Among the 170 K. pneumoniae clinical isolates, $55(32.4 \%)$ were ESBL producers; $92.7 \%(\mathrm{n}=51)$ and $72.7 \%(\mathrm{n}=40)$ of the isolates carried the $b l a_{\mathrm{SHV}}$ and $b l a_{\mathrm{TEM}}$ genes, respectively, and $67.3 \%(\mathrm{n}=37)$ carried both genes. The sequencing results showed that all $b l a_{\mathrm{TEM}}$ types were $b l a_{\mathrm{TEM}-1}$, except for two isolates that were $b l a_{\mathrm{TEM}-104}$. The $b l a_{\mathrm{SHV}}$ types were $b l a_{\mathrm{SHV}-1}, b l a_{\mathrm{SHV}-11}, b l a_{\mathrm{SHV}-12}, b l a_{\mathrm{SHV}-99}, b l a_{\mathrm{SHV}-108}$, and $b l a_{\mathrm{SHV}-110}$. Conclusions: The percentage of $b l a_{\mathrm{TEM}}$ and $b l a_{\mathrm{SHV}}$ among ESBL-producing $K$. pneumoniae isolates from Zahedan is relatively high, indicating the need for further surveillance and consideration in antibiotic use. To the best of our knowledge, this is the first report of TEM-104-, SHV-99-, SHV-108-, and SHV-110-type ESBLs among clinical isolates of K. pneumoniae from Iran, and TEM-1, SHV-1, SHV-11, and SHV-12 appear to be the dominant ESBLs in this region.
\end{abstract}

Keywords: Klebsiella pneumoniae. Extended-spectrum beta-lactamases. Antibiotic resistance.

\section{INTRODUCTION}

Klebsiella pneumoniae is an important opportunistic nosocomial pathogen responsible for a variety of infections, including urinary tract infections, pneumonia, septicemia, wound infections, and infections in intensive care units ${ }^{(1)}$. This bacterium is one of the leading causes of community-acquired and nosocomial infections and is associated with high mortality rates $^{(2)}$. The prevalence of $K$. pneumoniae with multi-drug resistance, which commonly leads to systemic infections and death, has been increasing in recent years ${ }^{(3)}$. The emergence of infections caused by these multidrug-resistant strains is a clinical challenge, with limited and complex treatment options ${ }^{(4)}$. Beta-lactam antibiotics (including penicillins, cephalosporins, carbapenems, or monobactams) have been widely applied in the treatment of serious infections caused by Gram-negative

Corresponding author: Dr. Shahram Shahraki-Zahedani.

e-mail: shahram17ir@yahoo.com

Received 31 March 2016

Accepted 11 July 2016 bacteria since the 1980 s, contributing to the rapid spread of bacteria resistant to these antibiotics worldwide ${ }^{(5)}$. The main mechanism of resistance is the production of beta-lactamases, which can protect bacteria against the lethal effect of betalactam antibiotics on cell wall synthesis ${ }^{(6)}$. Hydrolysis of betalactam antibiotics by beta-lactamases is the most common mechanism of resistance for this class of antibacterial agents in clinically important Gram-negative bacteria ${ }^{(7)}$. Extended spectrum beta-lactamases (ESBLs) were first described in 1983, which are capable of hydrolyzing oxyimino-cephalosporins (e.g., cefotaxime, ceftazidime, and ceftriaxone) and monobactams (e.g., aztreonam), but not cephamycins or carbapenems ${ }^{(8)}$. Betalactamase inhibitors (such as clavulanic acid, sulbactam, and tazobactam) prevent the action of ESBLs ${ }^{(9)}(10)$. Most of the genes encoding ESBLs are plasmid-borne and are often located in the transposons and integrons, which facilitates their mobilization with other resistance determinants. Thus, the genes encoding ESBLs may be easily transferred between bacteria. The most prevalent ESBLs are included in three groups: temoneira (TEM), sulfhydryl variable (SHV), and cefotaximase (CTX-M). The SHV enzymes are named after the thiol variable active 
site and are commonly associated with $K$. pneumoniae. The TEM enzyme was named after the patient from whom it was isolated, Temoneira, and was first discovered in Escherichia coli in Greece. In addition, chromosomal-related CTX-Mtype ESBL was reported in Kluyvera ascorbata ${ }^{(11)}$. Detection of ESBL production is important, because ESBL-positive strains are associated with increased mortality as compared to ESBL-negative strains. One major concern is the spread of ESBL-positive bacteria within hospitals, which may lead to outbreaks or to endemic occurrence. Another concern is the failure to treat infections caused by ESBL-positive organisms, as therapeutic choices are currently limited ${ }^{(1)}$. Detection of ESBLs by conventional antimicrobial susceptibility methods and delay in the detection and reporting of ESBL production by Gramnegative bacilli are associated with prolonged hospital stays, and increased morbidity, mortality, and healthcare costs ${ }^{(9)}$. Relatively little research on ESBL-producing bacteria has been conducted in the Southeastern region of Iran, and the resistance patterns of bacterial strains, especially the ESBL-producing mechanism, has not been determined in this region. Therefore, the aim of the present study was to evaluate the prevalence of TEM- and SHVtype ESBL-producing K. pneumoniae in Zahedan, Southeast Iran, using phenotypic and genotypic methods.

\section{METHODS}

\section{Isolation of bacteria}

Klebsiella pneumoniae isolates were obtained from 170 non-repetitive clinical samples, including urine, tracheal tube secretions, blood, wound secretions, urine catheter secretions, synovial fluid, and pharyngeal secretions, collected from patients referred to three teaching hospitals (Khatam al Anbiya, Ali ibn Abi Talib, and Buali) of Zahedan, Southeast Iran from January to December 2012. Collected samples were cultured on blood agar and MacConkey agar (Merck, Darmstadt, Germany) media. K. pneumoniae strains were identified based on standard microbiology methods such as Gram staining, oxidase and catalase tests, as well as biochemical tests with reference to standard tables ${ }^{(12)}$.

\section{Ethical considerations}

This study was evaluated and approved by the Ethics Committee of Zahedan University of Medical Sciences (project No. 90-17).

\section{Antimicrobial susceptibility testing}

The resistance profiles and antibiotic susceptibility of isolates were determined using the disc diffusion method (Kirby-Bauer) based on Clinical and Laboratory Standards Institute (CLSI) guidelines ${ }^{(13)}$. The antibiotic discs (MAST, Merseyside, UK) used were imipenem (10 $\mu \mathrm{g})$, amikacin $(30 \mu \mathrm{g})$, gentamicin $(10 \mu \mathrm{g})$, ciprofloxacin $(5 \mu \mathrm{g})$, ceftazidime $(30 \mu \mathrm{g})$, cefotaxime $(30 \mu \mathrm{g})$, cefpodoxime $(10 \mu \mathrm{g})$, ceftriaxone $(30 \mu \mathrm{g})$, aztreonam $(30 \mu \mathrm{g})$, cefepime $(30 \mu \mathrm{g})$, nalidixic acid $(30 \mu \mathrm{g})$, nitrofurantoin $(300 \mu \mathrm{g})$, co-trimoxazole $(25 \mu \mathrm{g})$, tetracycline $(30 \mu \mathrm{g})$, chloramphenicol $(30 \mu \mathrm{g})$, streptomycin $(10 \mu \mathrm{g})$, and colistin sulfate $(25 \mu \mathrm{g})$. Escherichia coli ATCC 25922 was employed for the quality control of antibiotic discs ${ }^{(14)}$.

\section{Screening for ESBL-producing isolates}

Based on the CLSI recommended method for screening of ESBL-producing isolates, the phenotypic confirmatory test was conducted with the disc diffusion method using discs containing cefotaxime $(30 \mu \mathrm{g})$ and cefotaxime/clavulanic acid $(30 / 10 \mu \mathrm{g})$, as well as those containing ceftazidime $(30 \mu \mathrm{g})$ and ceftazidime/ clavulanic acid $(30 / 10 \mu \mathrm{g})^{(14)}$.

\section{Measurement of the minimum inhibitory concentration of the isolates}

The minimum inhibitory concentration (MIC) values of four antibiotics, cefotaxime, ceftazidime, ceftriaxone, and cefpodoxime, were determined for isolates with an ESBLpositive phenotype using the E-Test method (Liofilchem MIC test strips, Italy). The concentration gradient for cefotaxime was $0.002-32 \mu \mathrm{g} / \mathrm{ml}$, and that for ceftazidime, ceftriaxone, and cefpodoxime was $0.016-256 \mu \mathrm{g} / \mathrm{ml}$. The interpretative criteria were applied following the E-test manufacturer's guidelines and according to CLSI recommendations. E. coli ATCC 25922 was used as a quality control for the MIC test strips ${ }^{(14)(15)}$.

\section{DNA extraction and polymerase chain reaction amplification}

After performing the MIC measurements and determining the resistant and ESBL-producing samples, the samples deemed resistant in the phenotypic confirmatory test were selected to evaluate the presence of the beta-lactamase genes $b l a_{\mathrm{TEM}}$ and $b l a_{\mathrm{SHV}} \mathrm{using}$ polymerase chain reaction (PCR). The plasmid deoxyribonucleic acid (DNA) of ESBLs-positive isolates, which was extracted with AccuPrep Plasmid Nano-Plus Plasmid Mini Extraction Kit Cat. No.: K-3112 (Bioneer, Daejeon, South Korea), was used for detection of the bla $a_{\text {TEM }}$ gene. In addition, the chromosomal DNA of isolates with an ESBLs-positive phenotype was isolated with the Molecular Biological System Transfer (MBST) DNA extraction kit (Iran), and used for detection of the $b l a_{\mathrm{SHV}}$ gene. The primers and PCR conditions described by Nasehi et al. ${ }^{(16)}$ were used to amplify the $b l a_{\text {TЕM }}$ and bla $_{\text {SHV }}$ genes $^{(16)}$.

\section{Sequencing of PCR products}

To confirm the accuracy of the test as well to determine the subtypes of the bla genes detected, samples testing positive for the $b l a_{\mathrm{TEM}}$ and $b l a_{\mathrm{SHV}}$ genes were sequenced by Bioneer Company, and the results were analyzed using the BLAST program (www.ncbi.nlm.-nih.gov5 BLAST).

\section{Statistical analysis}

The data were qualitatively described (percentage and frequency) using SPSS Software (version 18).

\section{RESULTS}

In this study, 170 isolates of $K$. pneumoniae were collected from three major hospitals of Zahedan: 128 (75.3\%) isolates from Khatam al Anbiya Hospital, 25 (14.7\%) isolates from Ali ibn Abi Talib Hospital, and 17 (10\%) isolates from Buali Hospital. Table 1 displays the pattern of antibiotic resistance of all isolates for the 17 different antibiotics tested.The rates 
TABLE 1

Antimicrobial susceptibilities of the Klebsiella pneumoniae isolates ( $\mathrm{n}=170)$.

\begin{tabular}{|c|c|c|c|}
\hline Antibiotic & $\frac{\text { Sensitive }}{n(\%)}$ & $\frac{\text { Intermediate }}{n(\%)}$ & $\frac{\text { Resistant }}{\text { n (\%) }}$ \\
\hline Cefepime & $118(69.4)$ & $15(8.8)$ & $37(21.8)$ \\
\hline Cefotaxime & $99(58.2)$ & $1(0.6)$ & $70(41.2)$ \\
\hline Ceftriaxone & $99(58.2)$ & $2(1.2)$ & $69(40.6)$ \\
\hline Ceftazidime & $100(58.8)$ & $11(6.5)$ & $59(34.7)$ \\
\hline Cefpodoxime & 98 (57.6) & $1(0.6)$ & $71(41.8)$ \\
\hline Aztreonam & $97(57.1)$ & $10(5.8)$ & $63(37.1)$ \\
\hline Imipenem & $156(91.8)$ & $6(3.5)$ & $8(4.7)$ \\
\hline Gentamicin & $126(74.1)$ & $0(0.0)$ & $44(25.9)$ \\
\hline Amikacin & $161(94.7)$ & $2(1.2)$ & $7(4.1)$ \\
\hline Streptomycin & $115(67.7)$ & $6(3.5)$ & $49(28.8)$ \\
\hline Tetracycline & $105(61.8)$ & $5(2.9)$ & $60(35.3)$ \\
\hline Ciprofloxacin & $126(74.1)$ & $10(5.9)$ & $34(20.0)$ \\
\hline Nalidixic acid & $108(63.5)$ & $22(13.0)$ & $40(23.5)$ \\
\hline Co-trimoxazole & 98 (57.6) & $0(0.0)$ & $72(42.4)$ \\
\hline Chloramphenicol & $154(90.6)$ & $0(0.0)$ & $16(9.4)$ \\
\hline Nitrofurantoin & $60(35.3)$ & 13 (7.6) & $97(57.1)$ \\
\hline Colistin sulfate & $168(98.8)$ & $0(0.0)$ & $2(1.2)$ \\
\hline
\end{tabular}

of resistance in K. pneumoniae isolates to ceftazidime, cefotaxime, ceftriaxone, cefpodoxime, and aztreonam antibiotics were $34.7 \%, 41.2 \%, 40.6 \%, 41.8 \%$, and $37.1 \%$, respectively.

Table 2 shows the pattern of antibiotic resistance of the ESBL-producing isolates. The maximum level of resistance was observed against cefpodoxime and cefotaxime (100\%), followed by ceftriaxone $(98.2 \%)$, co-trimoxazole $(89.1 \%)$, aztreonam $(81.8 \%)$, ceftazidime $(78.2 \%)$, tetracycline $(70.9 \%)$, streptomycin $(67.2 \%)$, gentamicin $(54.5 \%)$, cefepime $(41.8 \%)$, and nalidixic acid (43.6\%). Colistin sulfate, imipenem, amikacin, and chloramphenicol were associated with susceptibility values of $100 \%, 94.5 \%, 92.7 \%$, and $80 \%$, respectively, and were thus identified as the most effective antibiotics in the ESBLproducing isolates.

The phenotypic confirmatory test showed that among the 170 isolates, 55 (32.4\%) were ESBL producers. According to the CLSI criteria, if the MIC of cefpodoxime is $\geq 8$ or if the MICs of cefotaxime, ceftazidime, and ceftriaxone are $\geq 2$ for a bacterial strain, it can be considered as an ESBL producer ${ }^{(14)}$. Using these criteria, all 55 isolates were identified as ESBL producers to the four antibiotics mentioned above according to the MIC results.

The PCR assay of the ESBL-producing isolates indicated that $40(72.7 \%)$ isolates were positive for the $b l a_{\text {TEM }}$ gene, and $51(92.7 \%)$ isolates had the $b l a_{\mathrm{SHV}}$ gene. Moreover, 37 (67.3\%) of the isolates had both the $b l a_{\mathrm{TEM}}$ and $b l a_{\mathrm{SHV}}$. Figure1 and

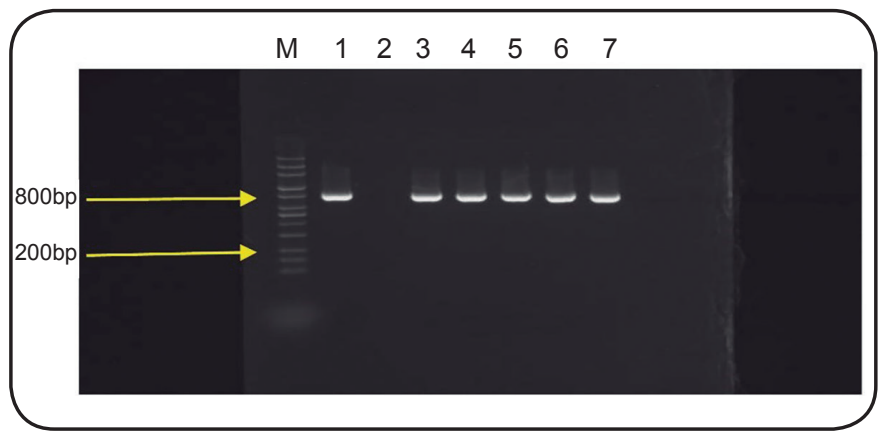

FIGURE 1. PCR amplification of the bla $_{\text {TEM }}$ gene. Lane M: $100 \mathrm{bp}-3 \mathrm{k} b$ ladder, lane 1: E. coli ATCC 35218 as a positive control; lane 2: E. coli ATCC 25922 as a negative control;lanes 3-7: bla $_{\text {ТЕM }}$-positive clinical isolates of K. pneumoniae;PCR: polymerase chain reaction; E.: Escherichia; K.: Klebsiella.

TABLE 2

Antimicrobial susceptibilities of ESBL-producing Klebsiella pneumoniae isolates $(\mathrm{n}=55)$.

\begin{tabular}{|c|c|c|c|}
\hline Antibiotic & $\frac{\text { Sensitive }}{n(\%)}$ & $\frac{\text { Intermediate }}{n(\%)}$ & $\frac{\text { Resistant }}{\text { n (\%) }}$ \\
\hline Cefepime & $18(32.7)$ & $14(25.5)$ & $23(41.8)$ \\
\hline Cefotaxime & $0(0.0)$ & $0(0.0)$ & $55(100.0)$ \\
\hline Ceftriaxone & $0(0.0)$ & $1(1.8)$ & $54(98.2)$ \\
\hline Ceftazidime & $1(1.8)$ & $11(20.0)$ & $43(78.2)$ \\
\hline Cefpodoxime & $0(0.0)$ & $0(0.0)$ & $55(100.0)$ \\
\hline Aztreonam & $0(0.0)$ & $10(18.2)$ & $45(81.8)$ \\
\hline Imipenem & $52(94.5)$ & $0(0.0)$ & $3(5.5)$ \\
\hline Gentamicin & $25(45.5)$ & $0(0.0)$ & $30(54.5)$ \\
\hline Amikacin & $51(92.7)$ & $0(0.0)$ & $4(7.3)$ \\
\hline Streptomycin & $15(27.3)$ & $3(5.5)$ & $37(67.2)$ \\
\hline Tetracycline & $15(27.3)$ & $1(1.8)$ & $39(70.9)$ \\
\hline Ciprofloxacin & $27(49.1)$ & $8(14.5)$ & $20(36.4)$ \\
\hline Nalidixic acid & $16(29.1)$ & $15(27.3)$ & $24(43.6)$ \\
\hline Co-trimoxazole & $6(10.9)$ & $0(0.0)$ & $49(89.1)$ \\
\hline Chloramphenicol & $44(80.0)$ & $0(0.0)$ & $11(20.0)$ \\
\hline Nitrofurantoin & $34(61.8)$ & $5(9.1)$ & $16(29.1)$ \\
\hline Colistin sulfate & $55(100.0)$ & $0(0.0)$ & $0(0.0)$ \\
\hline
\end{tabular}

ESBL: extended-spectrum $\beta$-lactamase.

Figure 2 shows the electrophoretic patterns of the $b l a_{\mathrm{TEM}}$ and $b l a_{\mathrm{SHV}}$ genes, respectively.

Overall, 91 positive PCR products, including 40 samples related to the $b l a_{\mathrm{TEM}}$ gene and 51 samples related to the $b l a_{\mathrm{SHV}}$ gene, were sequenced and analyzed. The majority of those positive for the $b l a_{\text {TEM }}$ gene were of the $b l a_{\text {TEM-1 }}$ subtype, with 


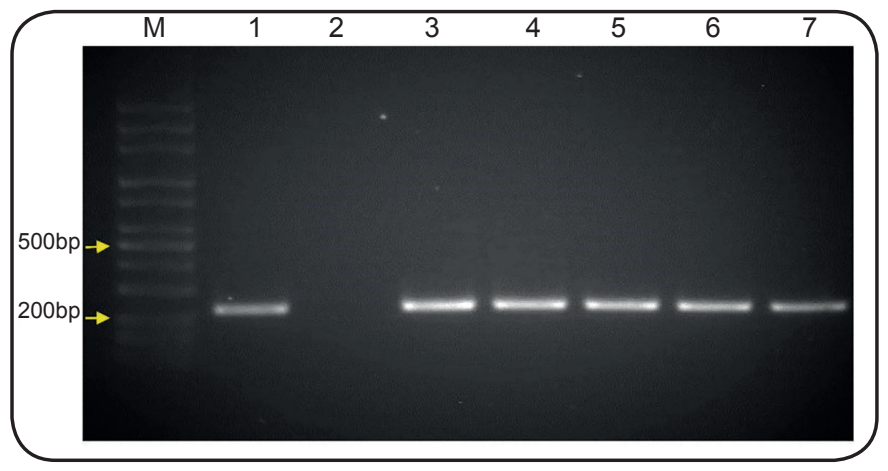

FIGURE 2. PCR amplification of the $b l a_{\mathrm{SHV}}$ gene. Lane M:100 bp-3k b ladder; lane 1: K. pneumoniae ATCC 700603 as a positive control; lane 2: E. coli ATCC 25922 as a negative control; lanes 3-7: bla $_{\mathrm{SHV}}$-positive clinical isolates of $K$. pneumoniae; PCR: polymerase chain reaction; $\boldsymbol{E}$. : Escherichia; $\boldsymbol{K}$. : Klebsiella

only two samples showing a different subtype, $b l a_{\mathrm{TEM}-104}$. Among the samples positive for the $b l a_{\mathrm{SHV}}$ gene, 17 samples were $b l a_{\mathrm{SHV}-11}$ subtype, 16 samples were $b l a_{\mathrm{SHV}-1}$ subtype, 14 samples were $b l a_{\mathrm{SHV}-12}$ subtype, 2 samples were $b l a_{\mathrm{SHV}-110}$ subtype, 1 sample was $b l a_{\mathrm{SHV}-99}$ subtype, and 1 sample was $b l a_{\mathrm{SHV}-108}$ subtype.

\section{DISCUSSION}

Resistance in Klebsiella pneumoniae strains to a wide spectrum of antibiotics is rapidly increasing. Therefore, awareness toward the prevalence and extent of resistant strains to antibiotics can help to determine the effectiveness of different antibiotics for the treatment of infections. The prevalence rate of infections caused by organisms that are resistant to betalactam antibiotics is increasing. Therefore, identification of ESBL-producing strains is a great necessity in both hospitals and the community ${ }^{(17)}$. In this study, the rates of resistance in K. pneumoniae isolates to ceftazidime, cefotaxime, ceftriaxone, cefpodoxime, and aztreonam antibiotics were higher than those reported by Ghafourian et al ${ }^{(18)}$, from isolates in Milad Hospital of Tehran (the capital of Iran), which were $65.8 \%, 46.4 \%$, $60.4 \%, 52 \%$, and $51 \%$, respectively, indicating a trend toward increasing resistance to these antibiotics in Iran. Furthermore, we identified an overall frequency of $32.4 \%$ ESBL producers, which is less than those reported in Turkey $(69 \%)^{(10)}$, Taiwan $(97 \%)^{(11)}$, India $(97 \%)^{(19)}$, Saudi Arabia $(55 \%)^{(20)}$, and Nepal $(62.7 \%)^{(21)}$, but higher than those reported in Lebanon $(20 \%)^{(22)}$, the United States $(7.6 \%)$, and Canada $(4.9 \%)^{(23)}$. Al-Agamy showed that the rates of resistance of ESBL-producing isolates to cefotaxime, ceftazidime, aztreonam, cefepime, gentamicin, amikacin, and ciprofloxacin were $97.7 \%, 95.5 \%, 97.7 \%, 47.8 \%$, $88.9 \%, 77.3 \%$, and $11.4 \%$, respectively, which supports our findings for cefotaxime, but indicates a higher resistance rate to the other antibiotics. Furthermore, Al-Agamy identified that all ESBL-producing isolates were susceptible to imipenem ${ }^{(20)}$, whereas in our study, 5.5\% of the ESBL-producing strains were resistant to imipenem. Although this is currently a small proportion, this finding can be considered a warning for the future, highlighting the necessity of further surveillance. In the present study, $100 \%$ of the ESBL-positive strains were resistant to cefotaxime and cefpodoxime, $98.2 \%$ were resistant to ceftriaxone, $81.8 \%$ were resistant to aztreonam, and $78.2 \%$ were resistant to ceftazidime, which is indicative of the overall high rate of antibiotic resistance in this region. Therefore, to prevent a further increase in the resistance to these antibiotics, prescriptions must be carefully considered in each case. According to our study, colistin sulfate, imipenem, amikacin, and chloramphenicol are more appropriate choices for the treatment of infections induced by ESBL-producing isolates, regardless of their side effects. Since these drugs are more expensive and can cause more complications, the accurate control and logical prescription of cephalosporins might result in better outcomes. The present study further showed that the $b l a_{\text {SHV }}$ gene is highly (92.7\%) prevalent in clinical ESBL-producing strains, and the most frequent subtypes were SHV-11, SHV-1, and SHV-12. In 2007, Al-Agamy et al. ${ }^{(20)}$ showed that $214(97.3 \%)$ of 220 strains isolated in Saudi Arabia carried the $b l a_{\mathrm{SHV}}$ gene, which is higher than that found in our study ${ }^{(20)}$. A study conducted by Ghafourian et al. ${ }^{(24)}$ in 2011 in Iran determined that 94\% of $K$. pneumoniae strains carried the $b l a_{\mathrm{SHV}}$ gene, which is in parallel with our results ${ }^{(24)}$. In recent years, the high relative prevalence of the bla ${ }_{\mathrm{SHV}}$ gene in ESBL-producing $K$. pneumoniae strains has been reported worldwide. The prevalence of ESBL-producing $E$. coli and $K$. pneumoniae isolates (TEM- and SHV-type ESBLs) was less than 1\% in 1997 in the Netherlands, which is a country known to employ antibiotics minimally; however, more recent studies indicate not only an increasing rate of resistance but also the emergence of new types such as SHV-31 in $K$. pneumoniae $^{(25)}$. In the present study, $72.7 \%$ of the strains carried the $b l a_{\text {TEM }}$ gene, and the major subtype was TEM-1. These results are similar to those reported in India and Turkey, with a prevalence of $73 \%$ and $73.4 \%$, respectively ${ }^{(10)(26)}$. Feizabadi et al. conducted a similar study on $K$. pneumoniae strains in Hospitals of Tehran in 2007, and also found that TEM-1, SHV-12, and SHV-1 were the most prevalent subtypes ${ }^{(27)}$. In a subsequent study, Feizabadi et al.(27) further identified that all of the $K$. pneumoniae isolates from a Labbafinejad Hospital that carried the $b l a_{\mathrm{TEM}}$ gene were the TEM-1 subtype, and TEM-1, SHV11, SHV-5, and SHV-12 were reported as the dominant ESBLs in resistant $K$. pneumoniae strains in $\operatorname{Iran}^{(28)}$. Overall, it seems that the majority of ESBLs in K. pneumoniae strains of Zahedan are derived from the $b l a_{\mathrm{SHV}}$ and $b l a_{\mathrm{TEM}}$ genes, with SHV-1, SHV-11, SHV-12, and TEM-1 as the most common subtypes. Moreover, the TEM-104, SHV-99, SHV-108, and SHV-110 subtypes were reported for the first time in Iran in this study. In conclusion, the prevalence of ESBLs is relatively high in the Southeast region in Iran, indicating that further studies are warranted to collect comprehensive epidemiological data of resistant strains.

\section{Conflict of interest}

The authors declare that there is no conflict of interest.

\section{Acknowledgments}

The authors appreciate all individuals who willingly participated in the current study. 


\section{Financial support}

This work was supported by a M.Sc. dissertation grant (M.Sc. thesis of Shahnaz Rigi) from Zahedan University of Medical Sciences.

\section{REFERENCES}

1. Ullah F, Malik1 SA, Ahmed J. Antimicrobial susceptibility pattern and ESBL prevalence in Klebsiella pneumoniae from urinary tract infections in the North-West of Pakistan. Afr J Microbiol Res 2009; 3:676-680.

2. Fung CP, Hu BS, Chang FY, Lee SC, Kuo BI, Ho M, et al. A 5-year study of the seroepidemiology of Klebsiella pneumoniae: high prevalence of capsular serotype K1 in Taiwan and implication for vaccine efficacy. J Infect Dis 2000; 181:2075-2079.

3. Otman J, Perugini ME, Tognim MCB, Vidotto MC. Atypical phenotypic characteristics of Klebsiella pneumoniae isolates from an outbreak in a neonatal intensive care unit in Brazil. Braz J Microbiol 2007; 38:273-277.

4. Fresno S, Jimenez N, Izquierdo L, Merino S, Corsaro MM, De Castro $\mathrm{C}$, et al. The ionic interaction of Klebsiella pneumoniae K2 capsule and core lipopolysaccharide. Microbiol 2006; 152:1807-1818.

5. Zaniani FR, Meshkat Z, NaderiNasab M, Khaje-Karamadini M, Ghazvini K, Rezaee A, et al. The Prevalence of TEM and SHV Genes among Extended-Spectrum Beta-Lactamases Producing Escherichia coli and Klebsiella pneumoniae. Iran J Basic Med Sci 2012; 15:654-660.

6. Song JS, Lee JH, Lee JH,Jeong BC,Lee WK,Lee SH. Removal of contaminating TEM-la beta-lactamase gene from commercial Taq DNA polymerase. J Microbiol 2006; 44:126-128.

7. Bush K, Jacoby GA. Updated functional classification of betalactamases. Antimicrob Agents Chemother 2010; 54:969-976.

8. Shahraki-Zahedani S, Moghadampour M, Bokaeian M, AnsariMoghaddam A. Prevalence of CTX-M-8 and CTX-M-15 type extended-spectrum beta-lactamases between Klebsiellapneumoniae spp. isolated from Zahedan, Southeast Iran. J Chemother 2016; 28:343-345.

9. Ejaz H, ul-Haq I, Zafar A, Mahmood S, Javed MM. Urinary tract infections caused by extended spectrum $\beta$-lactamase (ESBL) producing Escherichia coli and Klebsiella pneumoniae. Afr J Biotechnol 2011; 10:16661-16666.

10. Bali EB,Açik L, Sultan N. Phenotypic and molecular characterization of SHV, TEM, CTX-M and extended-spectrum $\beta$-lactamase produced by Escherichia coli, Acinobacter baumannii and Klebsiella isolates in a Turkish hospital. Afr J Microbiol Res 2010; 4:650-654.

11. Lin CF, Hsu SK, Chen CH, Huang JR, Lo HH. Genotypic detection and molecular epidemiology of extended-spectrum beta-lactamaseproducing Escherichia coli and Klebsiella pneumoniae in a regional hospital in central Taiwan. J Med Microbiol 2010; 59:665-671.

12. Podschun R, Ullmann U. Klebsiella spp. as nosocomial pathogens: epidemiology, taxonomy, typing methods, and pathogenicity factors. Clin Microbiol Rev 1998; 11:589-603.

13. Harada S, Ishii Y, Yamaguchi K. Extended-spectrum betalactamases: implications for the clinical laboratory and therapy. Korean J Lab Med 2008; 28:401-412.
14. Clinical and Laboratory Standards Institute (CLSI). Performance Standards for Antimicrobial Susceptibility Testing; Twenty-Fourth Informational Supplement. Clinical and Laboratory Standards Institute. Document M100-S24 2014; 34:1-230.

15. Schwalbe R, Steele-Moore L, Goodwin AC. Antimicrobial Susceptibility Testing Protocols. CRC Press 2007. p. 1-432.

16. Nasehi L, Shahcheragh F, Nikbin VS, Nematzadeh S. PER, CTX-M, TEM and SHV Beta-lactamases in clinical isolates of Klebsiella pneumoniae isolated from Tehran, Iran. Iranian J Bas Med Sci 2010; 13:111-118.

17. Gupta V. An update on newer beta-lactamases. Indian J Med Res 2007; 126:417-427.

18. Ghafourian S, Sadeghifard N, bin Sekawi Z, Neela VK, Nor Shamsudin M, Mohebi R, et al. Antimicrobial pattern and clonal dissemination of extended-spectrum beta-lactamase producing Klebsiella Spp isolates. Am J Infect Dis 2010; 6:110-121.

19. Lal P, Kapil A, Das BK, Sood S. Occurrence of TEM \& SHV gene in extended spectrum beta-lactamases (ESBLs) producing Klebsiella $s p$. isolated from a tertiary care hospital. Indian J Med Res 2007; 125:173-178.

20. Al-Agamy MHM, Shibl AM, Tawfik AF. Prevalence and molecular characterization of extended-spectrum $\beta$-lactamase-producing Klebsiella pneumoniae in Riyadh, Saudi Arabia. Ann Saudi Med 2009; 29:253-257.

21. Poudyal S, Bhatta DR, Shakya G, Upadhyaya B, Dumre SP, Buda G, et al. Extended spectrum a-lactamase producing multidrug resistant clinical bacterial isolates at National Public Health Laboratory, Nepal. Nepal Med Coll J 2011; 13:34-38.

22. Daoud Z, Hakime N. Prevalence and susceptibility patterns of extended-spectrum betalactamase-producing Escherichia coli and Klebsiella pneumoniae in a general university hospital in Beirut, Lebanon. Rev Esp Quimioter 2003; 16:233-238.

23. Jacoby GA, Munoz-Price LS. The new $\beta$-lactamases. N Engl J Med 2005; 352:380-391.

24. Ghafourian S, Bin Sekawi Z, Sadeghifard N, Mohebi R, Kumari Neela V, Maleki A, et al. The prevalence of ESBLs producing Klebsiella pneumoniae isolates in some Major Hospitals, Iran. Open Microbiol J 2011; 5:91-95.

25. Mazzariol A, Roelofsen E, Koncan R, Voss A, Cornaglia G. Detection of a new SHV-type extended-spectrum $\beta$-lactamase, SHV-31, in a Klebsiella pneumoniae strain causing a large nosocomial outbreak in The Netherlands. Antimicrob Agents Chemother 2007; 51:1082-1084.

26. Kamatchi C, Magesh H, Sekhar U, Vaidyanathan R. Identification of clonal clusters of Klebsiella pneumoniae isolates from Chennai by extended spectrum beta lactamase genotyping and antibiotic resistance phenotyping analysis. American J Inf Dis 2009; 5:74-82.

27. Feizabadi MM, Mahamadi-Yeganeh S, Mirsalehian A, Mirafshar SM, Mahboobi M, Nili F, et al. Genetic characterization of ESBL producing strains of Klebsiella pneumoniae from Tehran hospitals. J Infect Dev Ctries 2010; 4:609-615.

28. Feizabadi MM, Delfani S, Raji N, Majnooni A, Aligholi M, Shahcheraghi F, et al. Distribution of bla(TEM), bla(SHV), bla(CTX-M) genes among clinical isolates of Klebsiella pneumoniae at Labbafinejad Hospital, Tehran, Iran. Microb Drug Resist 2010; $16: 49-53$ 